\title{
A suspected malignant hyperthermia managed without dantrolene sodium
}

\author{
Bon-Sung Koo, Young-Kwon Kim, Sang-Hyun Kim, Jeong-Seok Lee, and Yong-Ik Kim
}

Department of Anesthesiology and Pain Medicine, Soonchunhyang University Bucheon Hospital, Soonchunhyang University College of Medicine, Bucheon, Korea

Malignant hyperthermia $(\mathrm{MH})$ is a hypermetabolic reaction that develops in individuals with sensitivity to inhalation anesthetics or depolarizing muscle relaxants [1]. The clinical manifestations of $\mathrm{MH}$ are characterized by muscle rigidity, hypercapnia, tachycardia, myoglobinuria, acidosis, rhabdomyolysis, and hyperthermia [1]. We herein report a suspected case of $\mathrm{MH}$ that manifested during general anesthesia.

A 61-year-old man was scheduled to undergo left lateral temporal bone resection, parotidectomy, and supraomohyoid neck dissection. He had no history of surgery. Preoperative laboratory, chest radiographic and electrocardiographic findings were normal. Upon arrival in the operating room, standard monitoring was applied. The baseline blood pressure (BP) and heart rate (HR) were 129/71 $\mathrm{mmHg}$ and $85 \mathrm{bpm}$, respectively. Anesthesia was induced with propofol and remifentanil. After tracheal intubation, anesthesia was maintained with sevoflurane, oxygen, and medical air. About $3 \mathrm{~h}$ after induction, the endtidal carbon dioxide $\left(\mathrm{ETCO}_{2}\right)$ gradually increased to $50 \mathrm{mmHg}$. At that time, the patient's esophageal temperature was $35.8^{\circ} \mathrm{C}$, and arterial blood gas analysis (ABGA) revealed a $\mathrm{pH}$ of 7.250 , $\mathrm{PCO}_{2}$ of $61.0 \mathrm{mmHg}$ (Table 1). First, we checked for bending or blockage of the breathing circuit. We found no signs of tracheal tube obstruction. The patient's respiratory rate and tidal volume were increased in an effort to decrease the $\mathrm{ETCO}_{2}$. However, the $\mathrm{ETCO}_{2}$ gradually increased and eventually maximized at 75 $\mathrm{mmHg}$. At $3 \mathrm{~h} 30 \mathrm{~min}$ after induction, hypotension and tachycardia developed, and the $\mathrm{ETCO}_{2}$ was still high $(77 \mathrm{mmHg})$. At this time, the patient's esophageal temperature abruptly increased to 38.8 from $36.2^{\circ} \mathrm{C} 10 \mathrm{~min}$ previously. ABGA showed a $\mathrm{pH}$ of $7.038, \mathrm{PCO}_{2}$ of $101.2 \mathrm{mmHg}$ (Table 1). Within $5 \mathrm{~min}$, the esophageal temperature reached $39.0^{\circ} \mathrm{C}$, and the tympanic membrane temperature was $39.2^{\circ} \mathrm{C}$. $\mathrm{MH}$ was suspected, and we promptly initiated the recommended therapy for $\mathrm{MH}$. Sevoflurane administration was immediately discontinued, and the patient was hyperventilated with $100 \%$ oxygen $(>10 \mathrm{~L} / \mathrm{min})$ through a non-rebreathing circuit. The anesthesia machine was quickly replaced with a machine that had not been exposed to inhalation anesthetic agents. Anesthetic maintenance was changed to a continuous infusion of propofol, and all means of lowering the temperature were used. Because dantrolene sodium was not available in our hospital, we called two medical centers that possessed this drug to deliver it to us as quickly as possible. The heating devices and heated circuit were removed. A Levin tube was inserted for cold saline irrigation. The axillary area was filled with ice packs, and the abdomen, both lower extremities and groin were massaged with ice water. Esmolol $(20 \mathrm{mg})$ was administered to control the HR. During the treatment, the highest $\mathrm{ETCO}_{2}$ was $102 \mathrm{mmHg}$, and the highest $\mathrm{BT}$ was $39.9^{\circ} \mathrm{C}$. Thirty minutes after the first detection of hyperthermia (at $4 \mathrm{~h}$ after induction), the patient's body temperature reached $39.8^{\circ} \mathrm{C}$. The arterial $\mathrm{pH}$ increased from 7.038 to 7.171 , and the $\mathrm{PCO}_{2}$ decreased from 101.2 to $75.8 \mathrm{mmHg}$ (Table 1). A complete blood cell count, coagulation profile, cardiac enzyme analysis, creatine kinase level, and urinalysis (including urine myoglobin) were then ordered. Laboratory findings were normal with the exception of an elevated serum myoglobin level. During the next 30 min, the $\mathrm{ETCO}_{2}$ decreased to $39 \mathrm{mmHg}$, and the patient's condition gradually stabilized (Table 1). The operation then resumed,

Corresponding author: Bon-Sung Koo, M.D., Department of Anesthesiology and Pain Medicine, Soonchunhyang University Bucheon Hospital, Soonchunhyang University College of Medicine, 170, Jomaru-ro, Wonmi-gu, Bucheon 420-767, Korea. Tel: 82-32-621-5330, Fax: 82-32-621-5322, E-mail: kbs0803@schmc.ac.kr

(c) This is an open-access article distributed under the terms of the Creative Commons Attribution Non-Commercial License (http:// creativecommons.org/licenses/by-nc/3.0/), which permits unrestricted non-commercial use, distribution, and reproduction in any medium, provided the original work is properly cited. 
Table 1. Intraoperative Arterial Blood Gas Analysis and Vital Signs

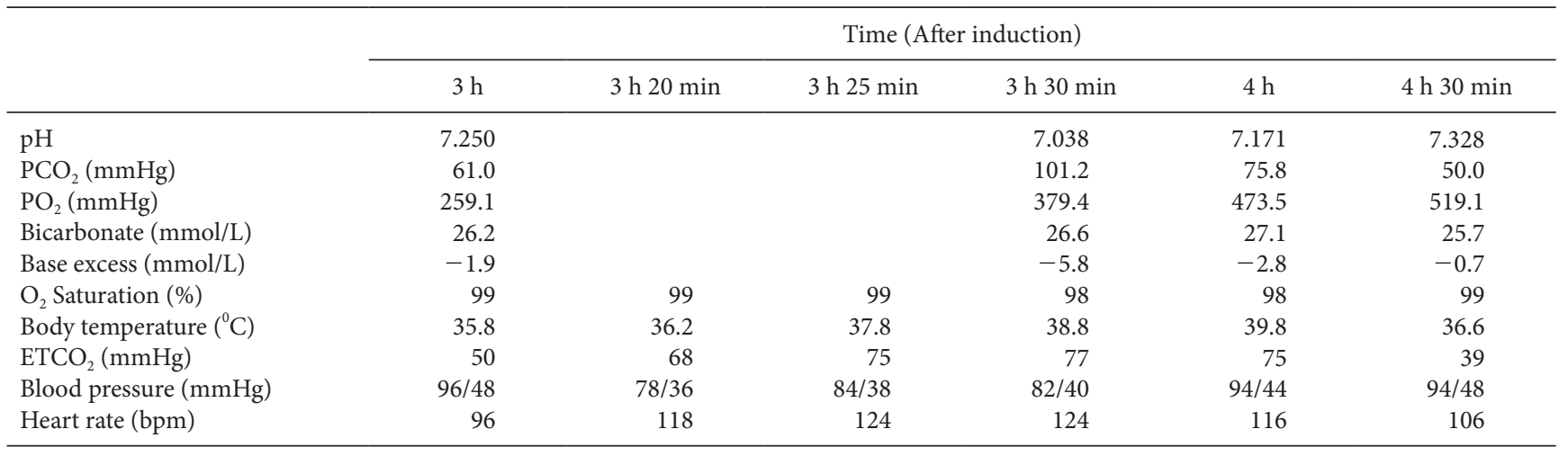

$\mathrm{ETCO}_{2}$ : end-tidal carbon dioxide, bpm: beat per minute.

and all vital signs remained within the reference range. The dantrolene sodium arrived at this point, but the patient's acute symptoms had improved. We decided not to use dantrolene sodium. No additional episodes were observed until the end of the operation. The patient was transferred to the intensive care unit to monitor any possible postoperative relapse of $\mathrm{MH}$. On postoperative day 1 , the patient was moved to the general ward. The patient was discharged 10 days postoperatively without specific complications.

In this patient, the presenting symptoms were an increase in the $\mathrm{ETCO}_{2}$ and tachycardia, both of which are nonspecific for $\mathrm{MH}$. We found no cause of the hypercapnia or tachycardia after exploring various possible causes. The increase in body temperature followed shortly thereafter. This helped us to diagnose $\mathrm{MH}$. It is well known that an abrupt increase in body temperature can be an important sign of $\mathrm{MH}$ [2]. However, it is a relatively late sign. Therefore, unexplained elevation in the $\mathrm{ETCO}_{2}$ can be a sensitive and the earliest symptom of $\mathrm{MH}$ [2]. Baudendistel et al. [3] reported two cases of $\mathrm{MH}$ in which the earliest sign was a rise in the $\mathrm{ETCO}_{2}$. They found that close monitoring of $\mathrm{ETCO}_{2}$ helped to achieve rapid diagnosis and treatment [3]. In our patient, despite the gradual adjustment of the minute ventilation, the $\mathrm{ETCO}_{2}$ eventually increased to an uncontrollable level. At that time, we associated the elevation of $\mathrm{ETCO}_{2}$ with the abnor- malities in other vital signs such as the body temperature and heart rate. We suspected $\mathrm{MH}$ based on the unexplained increase in the $\mathrm{ETCO}_{2}$ and the presence of tachycardia and hyperthermia.

In our patient, the onset of $\mathrm{MH}$ was late $(3 \mathrm{~h}$ after exposure to sevoflurane). There are agent-specific relationships between inhalational agents and the onset time of $\mathrm{MH}$ [4]. The time interval between induction of anesthesia and the development of clinical manifestations of $\mathrm{MH}$ may suggest the relative potency of the inhalation anesthetics triggering $\mathrm{MH}$ [4]. Hopkins [4] reported that the onset of the $\mathrm{MH}$ reaction to halothane is faster than that to enflurane and sevoflurane.

Dantrolene sodium is the treatment of choice for termination of $\mathrm{MH}$. In the current case, however, we did not administer this agent. According to a report by Larach [5] on $\mathrm{MH}$ that developed in patients in North America from 1987 to 2006, 22 of the total 286 patients recovered without dantrolene sodium. This implies that $\mathrm{MH}$ can be treated with symptomatic therapy only, as in the present case.

In conclusion, $\mathrm{MH}$ can occur slowly after exposure to sevoflurane with nonspecific symptoms such as hypercapnia and tachycardia and can progress to overt hyperthermia in a short period of time. Early recognition of $\mathrm{MH}$ and subsequent symptomatic treatment is important in that the patient can recover even without the use of dantrolene sodium.

\section{References}

1. Wappler F. Malignant hyperthermia. Eur J Anaesthesiol 2001; 18: 632-52.

2. Kim DC, Lim HR, Han YJ. Early recognition of malignant hyperthermia with capnography. Korean J Anesthesiol 2002; 43: 667-72.

3. Baudendistel L, Goudsouzian N, Cote' C, Strafford M. End-tidal CO2 monitoring. Its use in the diagnosis and management of malignant hyperthermia. Anaesthesia 1984; 39: 1000-3.

4. Hopkins PM. Malignant hyperthermia: pharmacology of triggering. Br J Anaesth 2011; 107: 48-56.

5. Larach MG, Gronert GA, Allen GC, Brandom BW, Lehman EB. Clinical presentation, treatment, and complications of malignant hyperthermia in North America from 1987 to 2006. Anesth Analg 2010; 110: 498-507. 